\title{
An empirical method to measure the relative efficiency of irrigation methods in agricultural industry
}

\author{
Mohammad Ebrahim MohammadPour zarandi ${ }^{\mathbf{a}^{*}}$, Neder Heydari ${ }^{\mathrm{b}}$ and Shahram RostamPour ${ }^{\mathrm{a}}$
}

${ }^{a}$ Department of Management Science, Islamic Azad University, Central Branch, Tehran, Iran

${ }^{b}$ Member of Research and Education of Ministry of Agricultural, Tehran, Iran

\section{A R T I C L E I N F O}

Article history:

Received June 25, 2011

Received in Revised form

August, 20, 2011

Accepted 22 August 2011

Available online

26 August 2011

Keywords:

Data Envelopment Analysis

Measuring relative efficiency

Irrigation method

Agricultural industry

Water resource management

\section{A B S T R A C T}

One of the most important issues affecting future world is managing the existing water resources. There is no doubt that global warming has created significant troubles on people's lives and it has caused shortage of water in the world. Therefore, we need to manage the water resources by allocating appropriate methods. In this paper, we use data envelopment analysis to measure the relative efficiency of fourteen different irrigation methods. The proposed model of this paper uses four inputs including cost, risk, maintenance and expertise and two outputs including flexibility and durability of irrigation methods. The preliminary results indicate that two surface irrigation methods, two sprinkler irrigation methods and one subsurface irrigation method are considered efficient. Other irrigation methods are only as much as 50 to 94 percent efficient compared with these five irrigation methods.

\section{Introduction}

During the past few years, there has been a tremendous increase on prices of foods in the world. Only in one year, from August 2010 to August 2011, the price of corn, coffee, soybean, rice and were up $71,38,36$ and 13 percents, respectively. The other challenging issue is the shortage of water resources and many believe that the future wars are not because of energy but because of water resources. Somali is one of the recent evidences of shortage of water in 2011, where people are losing their lives due to years of dryness. This increase motivates many people to optimize resources to reduce the cost of production in agricultural products, significantly.

Frija et al. (2011) investigated pricing policies and its impact on agricultural inputs demand in Tunisia using data envelopment analysis (DEA). They estimated farmers' individual irrigation water demand functions employing the information hidden in individual farmers' technical efficiency. This information is extracted through the development of a new deductive methodology based on inverse data envelopment Analysis (DEA) models. Their results indicated that farmers who were more

* Corresponding author. Tel: +989359821267

E-mail addresses: shrrsp@yahoo.com (S. Rostampour) 
technically efficient had less elastic irrigation water demand functions. They indicated that water pricing significantly affects inefficient irrigation methods. As a result, the farmers shift towards a various cropping pattern using substantially less water and more land, specially, when the price of water increases. Wang (2010) used DEA techniques to develop farm-level technical efficiency measures and sub-vector efficiencies for irrigation water use based on a sample data of 432 wheat farmers in northwestern China. They recommended that wheat farmers could generate the same quantity of wheat using the same quantity of inputs but with $69.35 \%$ less water.

Speelman et al. (2008) used DEA technique to measure the farm-level technical efficiency for water use and demonstrated that under constant returns to scale (CRS) and variable returns to scale (VRS) specification, significant technical inefficiencies, of $49 \%$ and $16 \%$, respectively, exist among farmers. Mousavi-Avval et al. (2011) presented a DEA based method to optimize energy consumption for soybean production. They used eight energy inputs including human labor, diesel fuel, machinery, fertilizers, chemicals, water for irrigation, electricity and seed energy and single output of grain yield. Based on the implementation of DEA method they ranked efficient and inefficient farmers and identified optimal energy requirement and wasteful uses of energy.

Mousavi-Avval et al. (2011), in other work, used DEA for improving energy use efficiency of canola production. In this study, they studied energy use pattern for canola production in Golestan province of Iran and the degrees of technical and scale efficiency of producers were analyzed using a nonparametric DEA method. They identified the wasteful uses of energy by inefficient farmers and suggested good savings in energy uses from different inputs. Nassiri and Singh (2009) in an assignment used DEA method for measuring energy use efficiency for paddy crop in India. They reported that small farmers had high energy-ratio and low specific energy requirement as compared to larger ones at paddy farms and there was strong correlation between energy-ratio and technical efficiency in both category-wise and zone-wise with correlation coefficient 0.98 and 0.99 , respectively.

The implementation of DEA also revealed that the correlation coefficient between specific energy and inverse technical efficiency were 0.97 and 0.99 for operation-wise and source-wise energy inputs for paddy crop, respectively. They explained despite the fact that there was high correlation between technical efficiency and energy-ratio, the comparison between correlation coefficient of farmers in different farm categories and different zones indicated that energy-ratio and specific energy were not enhanced indices for explaining of all kinds of the technical, pure technical and scale efficiency of farmers. Lilienfeld and heAsmild (2007) used DEA method for estimating of excess water use in irrigated agriculture in Iran. Hernández-Sancho and Sala-Garrido (2009) used DEA for measuring the relative efficiency and cost analysis in wastewater treatment processes.

In this paper, we present an empirical study to measure the relative efficiency of different irrigation methods using DEA technique. The organization of this paper first presents the proposed DEA model used in this research in section 2. Section 3 presents details of the implementation of our proposed study and concluding remarks are given in section 4 to summarize the contribution of this paper.

\section{Data envelopment method}

In this section, we explain the problem statement of the proposed DEA method. In a DEA method, there are normally some inputs and outputs associated with all decision-making units. Let $x_{i j}$ be the inputs for one of decision-making unit with $i=1, \ldots, m$ and $y_{r j}$ be the outputs of the same units with $r=1, \ldots, s$ and $j=1, \ldots, n$ and suppose $u_{i}$ and $v_{j}$ are the dual variables associated with $x_{i}$ and $y_{j}$, respectively. The constant return to scale DEA modeling formulation is as follows, 
$\max \quad z=\frac{\sum_{r=1}^{s} u_{r} y_{r .}}{\sum_{i=1}^{m} v_{i} x_{i .}}$

subject to $\frac{\sum_{r=1}^{s} u_{r} y_{r j}}{\sum_{i=1}^{m} v_{i} x_{i j}} \leq 1$.

$$
x_{i j}, y_{i j \geq 0}
$$

Model (1) is the one of the well known DEA, which can be solved $j$ times to determine the relative efficiencies of various units. However, since model (1) is nonlinear in structure, Charles et al. (1978) proposed a simple modification of the objective function to convert model (1) into a simple linear programming problem as follows,

$$
\begin{array}{ll}
\max & z=\sum_{r=1}^{s} u_{r} y_{r .} . \\
\text { subject to } & \frac{\sum_{r=1}^{s} u_{r} y_{r j}}{\sum_{i=1}^{m} v_{i} x_{i j}} \leq 1 . \\
& \sum_{i=1}^{m} v_{i} x_{i .}=1 \\
& u_{r}, v_{i} \geq 0, \quad j=1, \ldots, n
\end{array}
$$

Problem (2) has been widely used for many water resources management studies. DEA models have been extended when there are uncertainties associated with inputs/outputs called robust DEA. In robust DEA we consider an acceptable perturbation on each parameters and final solution will not change as long as these parameters change in the interval of uncertainties (Roghanian \& Foroughi, 2010).

\section{Empirical analysis}

During the past few years, there are different methods of irrigations such as surface, sprinkler, subsurface, localized. Every method has various characteristics, which could be measured in terms of cost, maintenance, expertise and the risk associated with using these methods. These issues are considered as inputs of the system. In addition, the flexibility and durability of irrigation are other important factors, which are considered as outputs for the implementation of DEA techniqe. The proposed DEA model of this paper uses four inputs and two outputs to measure the relative efficiencies of different decision-making units and Fig. 1 shows the input/output parameters.

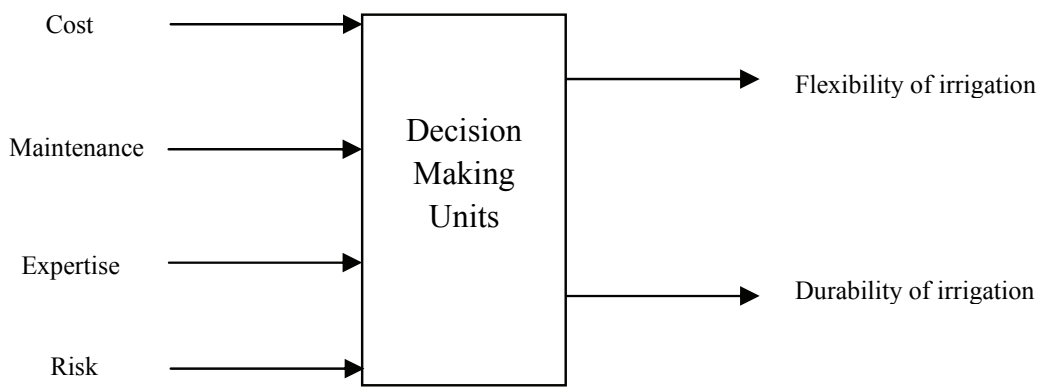

Fig. 1. The inputs and the outputs of the proposed DEA model 
As we can observe from Fig. 1, some of the input parameter such as cost can be directly measured but some others need more investigation for assigning a number. We define Likert scale so that we could provide a better assessment for them. There are some irrigation equipments, which are somewhat complicated to use and perform maintenance. We have considered expertise as an input and assign one as long as the irrigation equipment can be repaired by farmer, two is assigned when a local producer is entitled to provide supporting facilities, three is assigned for irrigation equipment, which needs to be sent to specific shop for maintenance and four in case irrigation equipment is required to be sent to an agent.

For the case of maintenance, first, we consider a number from one to five, where one is for maintaining equipment with simple farmer's skills and five is for equipment, which needs a specialist for maintenance. The numbers 2, 3 and 4 are assigned for equipments depending on how difficult is to maintain them. Second, we consider another number from one to ten, which represent the amount of efforts we need to put into to maintain equipment. In case, an irrigation equipment can be repaired with some simple care in minimum amount of time we assign a number one and when we need to spend substantial amount efforts in considerable amount of time we assign a number ten. The other numbers between one to ten are considered based on the level of efforts. The maintenance number is calculated by multiplying the numbers are obtained from the first and the second stage of this process.

The risk assessment is indentified by decision maker in three categories of low(1), medium(2) and high(3) depending on the degree of risk associated with the equipment. In terms of flexibility, when an equipment can be easily implemented we consider three and for an equipment with no flexibility we consider one. Obviously, a number 2 is assigned for anything with some flexibility. The durability is divided in five Likert scale and a number one is assigned for breakable equipment and five for equipment, which could be used for years.

Table 1 summarizes different characteristics of 14 different irrigation methods used for the proposed study of this paper.

Table 1

Characteristics of input/output DEA method for different decision making units (DMUs)

\begin{tabular}{|c|c|c|c|c|c|c|c|}
\hline \multirow{2}{*}{$\begin{array}{l}\text { Irrigation } \\
\text { method }\end{array}$} & \multirow[b]{2}{*}{ DMU } & \multicolumn{4}{|c|}{ Inputs } & \multicolumn{2}{|r|}{ Outputs } \\
\hline & & Risk & Cost & Expertise & Maintenance & Flexibility & Durability \\
\hline \multirow{3}{*}{ Surface } & 1 & 1 & 6885 & 2 & 20 & 3 & 5 \\
\hline & 2 & 1 & 4635 & 1 & 24 & 3 & 5 \\
\hline & 3 & 1 & 4200 & 1 & 30 & 3 & 5 \\
\hline \multirow{7}{*}{ sprinkler } & 4 & 2 & 563 & 3 & 9 & 3 & 3 \\
\hline & 5 & 2 & 775 & 3 & 15 & 2 & 3 \\
\hline & 6 & 3 & 1150 & 3 & 18 & 2 & 3 \\
\hline & 7 & 2 & 1075 & 1 & 8 & 3 & 1 \\
\hline & 8 & 2 & 2975 & 2 & 5 & 3 & 3 \\
\hline & 9 & 3 & 900 & 4 & 5 & 1 & 2 \\
\hline & 10 & 3 & 1825 & 4 & 10 & 1 & 2 \\
\hline \multirow{3}{*}{ Localized } & 11 & 1 & 2100 & 2 & 20 & 3 & 4 \\
\hline & 12 & 3 & 2400 & 2 & 10 & 3 & 4 \\
\hline & 13 & 3 & 4300 & 2 & 15 & 3 & 4 \\
\hline subsurface & 14 & 3 & 2200 & 2 & 24 & 3 & 1 \\
\hline
\end{tabular}

As we can observe from Table 1, we have assigned Likert based numbers for some inputs and outputs while we have used actual numbers in the case of cost measured in terms of dollar per acres.

We have used constant to scale DEA method (Charnes et al., 1978, 1994) to estimate the relative efficiencies of all 14 units and the results are summarized in Table 2. 
Table 2

Details of relative efficiencies of 14 decision making units (DMUs)

\begin{tabular}{lcccccccccccccc}
\hline DMU & 1 & 2 & 3 & 4 & 5 & 6 & 7 & 8 & 9 & 10 & 11 & 12 & 13 & 14 \\
\hline Efficiency & 1.0 & 0.89 & 1.0 & 0.5 & 0.79 & 0.94 & 0.67 & 0.7 & 1.0 & 1.0 & 0.71 & 0.54 & 0.84 & 1.0 \\
Rank & 1 & 31 & 1 & 10 & 5 & 2 & 8 & 7 & 1 & 1 & 6 & 9 & 4 & 1 \\
\hline
\end{tabular}

As we can observe from Table 2, there are five efficient units, 1, 3, 9, 10 and 14. The other units represent different efficiencies compared with efficient ones. From an inefficient unit 4 with a relative efficiency of 0.50 to unit 6 with an efficiency of 0.94 , we can see that there are different inefficient units used among farmers, which could lead to significant waste of water resources. The surface irrigation includes Basin, Border and Furrow and the Basin and Furrow are considered the efficient ones. Among seven types of sprinkler irrigation methods, only center pivot system and linear move system were efficient. Finally, subsurface, which includes only one single method is the last efficient unit. Based on the results, it is obvious that a governmental regulation for devoting loan to purchase efficient facilities could help farmers reduce water consumption.

\section{Conclusion}

In this paper, we have presented an empirical study to measure the relative efficiencies of different irrigations using data envelopment analysis. The proposed study of this paper used four methods of surface, sprinkler, localized and sub-surface with their subdivisions. The proposed DEA method incorporated four inputs including cost, risk, expertise and maintenance, where three were measured using Likert scale and one item, cost, was measured using dollar value per acres. The proposed model used two outputs of flexibility and durability of different methods as important outputs of the DEA model and the outputs were measured using Likert scale. The DEA model was solved using constant to return scale model and the results indicated that only five methods of irrigation could be efficient. The results of this paper not only helps farmers find better and efficient units but also it could help government provide special regulation to encourage farmers use efficient equipments.

\section{Acknowledgment}

The authors would like to thank the anonymous referees for their constructive comments on earlier version of this paper.

\section{References}

Charnes A, Cooper, W. W., \& Rhodes, E. (1978). Measuring the efficiency of decision making units. European Journal of the Operational Research, 2, 429-444.

Charnes A, Cooper W. W., Lewin, A., \& Seiford, L. M. (1994). Data envelopment analysis: theory, methodology and applications. Massachusetts: Kluwer Academic Publishers.

Frija, A., Wossink, A., Buysse, J., Speelman, S., \& Van Huylenbroeck, G. (2011). Irrigation pricing policies and its impact on agricultural inputs demand in Tunisia: A DEA-based methodology. Journal of Environmental Management, 92(9), 2109-2118.

Hernández-Sancho, F., \& Sala-Garrido, R. (2009). Technical efficiency and cost analysis in wastewater treatment processes: A DEA approach. Desalination, 249(1), 230-234.

Likert, R. (1932). A Technique for the Measurement of Attitudes. Archives of Psychology, 140, 1-55.

Lilienfeld, A., \& Asmild, M. (2007). Estimation of excess water use in irrigated agriculture: A data envelopment analysis approach. Agricultural Water Management, 94(1-3), 73-82.

Mousavi-Avval, S.H., Rafiee, S., Jafari, A., \& Mohammadi, A. (2011). Optimization of energy consumption for soybean production using Data Envelopment Analysis (DEA) approach. Applied Energy, 88(11), 3765-3772. 
Mousavi-Avval, S.H., Rafiee, S., Jafari, A., \& Mohammadi, A. (2011). Improving energy use efficiency of canola production using data envelopment analysis (DEA) approach. Energy, 36(5), 2765-2772.

Nassiri, S.M., Singh, S. (2009). Study on energy use efficiency for paddy crop using data envelopment analysis (DEA) technique. Applied Energy, 86(7-8), 1320-1325.

Roghanian, E. \& Foroughi, A. (2010). An empirical study of Iranian regional airports using robust data envelopment analysis. International Journal of Industrial Engineering Computations, 1(1), 65-72.

Wang, X.Y. (2010). Irrigation water use efficiency of farmers and its determinants: Evidence from a survey in northwestern China. Agricultural Sciences in China, 9(9), 1326-1337.

Speelman, S., D'Haese, M., Buysse, J., \& D'Haese, L. (2008). A measure for the efficiency of water use and its determinants, a case study of small-scale irrigation schemes in North-West province, South Africa. Agricultural Systems, 98(1), 31-39. 